\title{
Lapurdum
}

Euskal ikerketen aldizkaria | Revue d'études basques |

Revista de estudios vascos | Basque studies review

$17 \mid 2013$

Numéro XVII

\section{Le préjugé ethnique pour conviction. La défense de la République française par la disqualification du monde basque}

\section{Thomas Pierre}

\section{(2) OpenEdition}

\section{Édition électronique}

URL : https://journals.openedition.org/lapurdum/2437

DOI : 10.4000/lapurdum.2437

ISSN : 1965-0655

Éditeur

IKER

Édition imprimée

Date de publication : 1 octobre 2013

Pagination : 175-185

ISBN : 978-2-86781-409-9

ISSN : 1273-3830

Référence électronique

Thomas Pierre, «Le préjugé ethnique pour conviction. La défense de la République française par la disqualification du monde basque », Lapurdum [En ligne], 17 | 2013, mis en ligne le 15 novembre 2015, consulté le 22 juillet 2021. URL : http://journals.openedition.org/lapurdum/2437 ; DOI : https://doi.org/ 10.4000/lapurdum.2437 


\title{
Le préjugé ethnique pour conviction : La défense de la République française par la disqualification $\mathrm{du}$ monde basque
}

\author{
Thomas PIERRE \\ Laboratoire d'Anthropologie des Institutions et Organisations \\ Sociales (LAIOS)/Institut Interdisciplinaire d'Anthropologie du \\ Contemporain (IIAC-UMR 8177)
}

\section{Introduction}

En Pays basque de France, les revendications de création d'une institution territoriale et de co-officialisation de la langue basque interrogent la légitimité du lien entre sphère

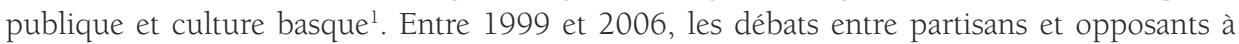
cette reconnaissance ont essentiellement pour objet de divergence la revendication de création

1.- J'entends par les expressions culture basque et monde basque, l'espace des pratiques et représentations au sein duquel il est fait référence à ce qui est vécu, pensé et/ou perçu comme étant basque. Pour désigner le Pays basque de France, nous utiliserons aussi indistinctement les expressions Pays basque français et Pays basque nord. La co-officialisation de la langue basque doit permettre la reconnaissance légale de son utilisation dans tous les services publics, à égalité de traitement avec la langue française. Du point de vue institutionnel, à partir de 1992, la France s'oppose à la Charte européenne des langues régionales ou minoritaires qui consacre « le droit imprescriptible de pratiquer une langue régionale dans la vie privée et publique » (http://conventions.coe.int/treaty/fr/Treaties/Html/148.htm). Celle-ci est néanmoins adoptée à la majorité des membres du Conseil de l'Europe et la France reste l'un des rares États d'Europe à ne pas l'avoir ratifiée. Depuis, la révision constitutionnelle du 23 juillet 2008 affirme : « Les langues régionales appartiennent au patrimoine de la France »- Article 75-1 de la Constitution du 4 octobre 1958 (http://www.legifrance.gouv. $\mathrm{fr} / \mathrm{html} /$ constitution/constitution2.htm). Les données ethnographiques sur lesquelles s'appuie cet article sont issues de mes recherches effectuées dans le cadre de ma thèse de doctorat en Anthropologie sociale et Ethnologie (Pierre, 2010). Le contenu de cet article fut l'objet d'une communication (intitulée « Instrumentalisations et reformulations d'un concept : l'autochtonie basque ») présentée le vendredi 29 novembre 2013 dans le cadre du colloque L'autochtonie : un concept à déployer organisé à l'Université de Pau et des Pays de l'Adour (UPPA) par la Fédération de recherche Espaces, Frontières, Métissages. 
d'un Département Pays Basque².

Pour comprendre les arguments alors usités à ce sujet à l'échelle locale, il nous faut témoigner de ce suppose, à l'échelle nationale française, la distinction classique entre Nation et Région avant de rendre compte de ce que cette opposition implique à l'échelle locale. En effet, nous nous intéresserons tout particulièrement au discours de l'opposition à toute inscription du territoire et de la langue basque dans la sphère publique. Dans quelle mesure ce discours est-il construit en référence aux valeurs dites « républicaines »? Dans quelle mesure le recours aux idées des Lumières - et, donc, le rejet de tout ce qui apparaît comme les contestant conditionne-t-il les débats sur l'institutionnalisation du Pays basque nord ? Dans quelle mesure l'autochtonie basque est-elle instrumentalisée comme envers de la citoyenneté française?

\section{La distinction citoyenneté/ethnicité : le civilisé politique et l'autochtone ethnique}

Dès le début des années quatre-vingt et l'arrivée au pouvoir du Parti Socialiste, les gouvernements successifs ont affirmé la nécessité de donner une place à la pluralité culturelle et linguistique « régionale » au sein de l'État français. Mais cette volonté n'aboutit pas (Oronos : 2002). Depuis la mise en place de l'article 2 de la Constitution, toute revendication de reconnaissance linguistique est considérée comme anti-constitutionnelle. Larticle 2 de la Constitution stipule que « la langue de la République est le français ». Il est ajouté en 1992, à l'initiative de Jacques Toubon et d'Alain Lamassoure, député européen et du département des Pyrénées-Atlantiques. Au départ, il était en effet officiellement présenté comme un moyen de traduire dans la loi la notion « d'exception culturelle française » dans la perspective de protéger la langue française de la concurrence de la langue anglaise. Mais l'article est aujourd'hui largement utilisé pour justifier les oppositions aux revendications d'inscription des langues régionales dans la sphère publique. Le jeudi 21 novembre 2002 par exemple, il fait l'objet d'un débat à l'Assemblée Nationale. Deux amendements - présentés par les députés UMP Marc Le Fur et UDF François Bayrou, lui aussi, député des Pyrénées-Atlantiques -, qui proposent « le respect (et la défense) des langues et cultures régionales de France », sont rejetés pour ce motif anticonstitutionnel ${ }^{3}$. Comment doit-on interpréter la manifestation et la permanence de ce blocage institutionnel?

2.- Cette revendication est alors soutenue des milieux basquisants très divers : représentants locaux des partis politiques nationaux (à l'exception du Parti Communiste et du Front National), partis politiques et associations nationalistes basques, mouvements culturels basques. Le projet départementaliste suscite alors localement et ponctuellement des polémiques relativement passionnées quant au bien-fondé ou non de la reconnaissance politique du territoire et de la langue basque en France. À cette époque, les trois provinces basques françaises (le Labourd, la Basse-Navarre et la Soule) ne bénéficient que du statut non-contractuel de « Pays », tel qu'institué par la « loi Pasqua » du 4 février 1995 sur l'orientation et l'aménagement du territoire, laquelle précise dans son article 23, que « le Pays exprime la communauté d'intérêts économiques et sociaux ainsi que, le cas échéant, les solidarités réciproques entre les villes et l'espace rural ». La délimitation territoriale de ce « Pays », baptisé « Pays «Pays Basque» », a été directement inspirée du tracé prérévolutionnaire des trois provinces basques françaises. Dans le cadre de ce statut public, la langue basque (euskara) ne bénéficie d'aucune reconnaissance institutionnelle.

3.- «L'assemblée nationale rejette la reconnaissance de nos langues dans la Constitution », Enbata, n 1754,28 novembre 2002. 
En premier lieu, l'introduction politique de la pluralité linguistique et culturelle dans l'organisation de l'État met en question une donnée fondamentale de l'État-nation français. En effet, le projet de Révolution consistait à donner corps à la nation par la langue française en tant que langue commune. La propagation de la langue française est alors perçue comme la condition nécessaire au développement de l'égalité des chances entre citoyens au sein de l'État (Certeau, Julia, Revel, 1975). Mais la langue française ne fut, et n'est pas qu'un outil destiné à favoriser l'égalité sociale. Elle est investie d'une valeur symbolique majeure. Il s'agit d'instituer le peuple français par la diffusion de la langue unique ${ }^{4}$. Nous sommes alors en présence d'une conception de la nation, partiellement déterminée par un critère culturel, la langue, et non strictement par une adhésion à des valeurs politiques. Cette conception de l'État-nation demeure aujourd'hui la conception dominante et consensuelle en France. C'est en référence à cette conception de la nation que l'opposition à la départementalisation du Pays basque $^{5}$ considère que la reconnaissance de la langue basque (euskara) impliquerait également celle d'un territoire, le Pays Basque, ainsi que celle d'un groupe (les Basques). Au final, ce type de reconnaissance introduirait une relation conflictuelle entre deux interprétations de la nation. C'est pourquoi, dans ses réponses aux revendications linguistiques régionalistes, le Conseil constitutionnel fait régulièrement référence à l'article 2 de la loi fondamentale, selon lequel « la langue de la République est le français».

Aussi, le Conseil ne conçoit pas que les citoyens français puissent avoir le droit, dans la vie publique, de pratiquer une autre langue que le français. Ce raisonnement tend à laisser penser que le Conseil définit la nation non pas par le strict partage de valeurs politiques mais également par le partage d'une réalité linguistique, l'usage collectif du français. Dans ce cadre, la conception républicaine de la nation française est culturalisée. La profondeur historique de cette conception de l'État-nation et sa vigueur maintenue expliquent la paralysie du pouvoir

4.- La langue française ne définit le peuple français que dans une certaine mesure : les Belges, les Québécois ou d'autres ne sont, en effet, pas considérés comme français. En cela, le cas du français diverge de celui de la langue allemande, qui, elle, définit le peuple.

5.- La revendication de départementalisation a suscité la création de deux associations. Dans un premier temps, en septembre 1999, à l'initiative de Jacques Betbeder, l'association Citoyens en Adour-Pyrénées Vivre-Ensemble se constitue en réaction à la campagne départementaliste de l'Appel des Cent. Il s'agit pour cette association de réaffirmer l'attachement, qu'elle pense majoritaire, de la population au statu-quo institutionnel, au maintien du Pays basque et du Béarn au sein d'un même département, celui des Pyrénées-Atlantiques. L'association dit vouloir dénoncer la tendance au développement de valeurs communautaristes et d'aspirations « ethnicistes » au sein de la société française dont le mouvement associatif départementaliste serait l'incarnation locale. Jusqu'en octobre 2003, cette association est la seule structure associative à s'opposer catégoriquement et publiquement aux réformes institutionnelles soutenues par les départementalistes. Mais, à partir d'octobre 2003, alors que le mouvement Batera se met en place, naît, parallèlement, le Cercle Lissagaray. Le Cercle Lissagaray se veut être un club de réflexion créé par Jean Espilondo, député et conseiller général socialiste d'Anglet-nord, Christian Aguerre, ancien rédacteur en chef de l'hebdomadaire La Semaine du Pays Basque, Jean-Claude Paul-Dejean, ancien professeur d'Histoire et Pierre Bidart, universitaire et responsable des Éditions Izpegi. Le nom retenu pour baptiser ce cercle est symbolique : Prosper-Olivier Lissagaray, né en 1839 à Auch de famille basque et décédé à Paris en 1901, est un journaliste du XIXe siècle qui s'engagea sous l'Empire et combattit pour la Commune sur les barricades. Socialiste, républicain, proche des idées de Blanqui, il n'appartint à aucun parti. Le choix de ce personnage semble tout à fait correspondre à ce que l'anti-départementalisme veut prouver : on peut, au Pays basque, être Basque (le nom Lissagaray en atteste) et républicain (en référence à la France en tant qu'État-nation de tradition jacobine). 
politique en la matière. La difficulté majeure à laquelle se heurte le processus de reconnaissance des langues régionales provient de la conception même de la nation sur laquelle la Constitution se fonde. À partir du moment où l'on conçoit la communauté nationale selon une logique culturelle - du moins partiellement -, on est conduit à ne concevoir l'existence collective de groupes au sein de cette nation qu'à partir d'une logique communautariste. En France, la référence que l'on fait volontiers à l'idée de nation comme produit politique, fondé sur des normes et des valeurs qui définissent la citoyenneté, est intimement mêlée à un imaginaire collectif qui rassemble les images d'une histoire largement mythique. Le rôle accordé à la langue nationale est originaire et reste central dans cette construction. Ainsi, du point de vue factuel, l'opposition entre la conception ethniciste de la nation - qui serait revendiquée par le nationalisme basque et dont le départementalisme basque serait l'héritier -, et celle dont l'État français aurait le secret, exclusivement issue d'une adhésion librement consentie à un ensemble de valeurs politiques, ne tient pas.

Cette assimilation initiale entre appartenance politique et caractéristiques linguistiques a des répercussions importantes sur les représentations de l'identité basque en Pays basque nord dans la mesure où la citoyenneté française est fortement caractérisée par la confusion entre nationalité et citoyenneté. Appartenances culturelles et politiques sont confondues : la citoyenneté et l'identité nationale culturelle - notamment par l'intermédiaire du statut constitutionnel de la langue française - sont souvent perçues et vécues comme ne faisant qu'un.

Il en résulte un a priori conflictuel qui tend à opposer la communauté politique citoyenne nationale aux communautés autochtones considérées comme « ethniques » et « régionales». La vulgarisation de l'idéologie républicaine contribue à reléguer dans la seule sphère privée les cultures dites « ethniques » considérées par nature comme antagonistes et en concurrence avec l'espace politique de la sphère publique. Selon Michel Wieviorka, « au fil des années 90, l'idée républicaine a alimenté des discours de plus en plus ardents, au point d'aboutir à une perversion : le républicanisme. Ses tenants les plus radicaux ont désigné des «casseurs» de la République, ils ont accusé [...] de communautarisme les démocrates favorables à une écoute politique des demandes liées à des particularismes culturels. Intransigeant, autoritariste, élitiste dans ses positions, [...] le républicanisme développe une vision mythique de la société et de l'histoire. [...] Il embellit le passé de la République jusqu'à en faire un âge d'or onirique $\aleph^{6}$. Cette sacralisation de l'idée de République est très courante dans les discours de l'opposition à la reconnaissance territoriale du Pays basque nord, elle sert à dénoncer le caractère supposé nécessairement communautariste des revendications basques. En janvier 2000, un opposant, membre bayonnais de l'association CAP Vivre-Ensemble explique qu'il :

« croit à la France simplement parce que justement elle n'est pas bâtie sur une race. J'entends des gens - selon lui, les militants basquisants - dont l'idéologie est basée sur cela, sur une espèce de race quelque part, ou d'ethnie, ou de je ne sais pas quoi. Au contraire, la France est une communauté de destin basée sur des ethnies ou populations très diverses qui 
acceptent un cadre commun. Le jour où ils ne l'accepteront pas, peut-être que c'est demain, je n'en sais rien, on verra,... et bien tout sera dit. Par contre, je serai inquiet ce jour-là parce que ce sera, à mon avis, le retour des tribus, et de la loi de la jungle. S'il n'y a pas un certain ordonnancement sur des bases, des principes, on va dire sur l'esprit des Lumières ou même en remontant avant, eh bien, à mon avis, on va au-devant des problèmes d'affrontements que l'on voit ailleurs, et puis que l'on a vu en Europe, il n'y a pas longtemps $»^{7}$.

Dans la perspective de défendre l'application des idées républicaines en Pays basque, notre témoin n'inscrit ce qu'il perçoit comme relevant de la culture non-nationale - en l'occurrence ici, la culture basque - qu'en référence à l'idée de race, qu'en référence à la nature par le biais de la figure symbolique de la «tribu». Cette supposée tribu - métaphore de l'idée d'ethnie basque - est par ailleurs animalisée, elle évolue au sein de la « jungle » et non pas de la cité. Elle relève de la nature et non pas de la culture. Elle relève exclusivement de l'inné et, en aucun cas, de l'acquis. Elle n'existe que par essence. Ce discours est un discours paternaliste classique qui s'appuie sur la version ethnologisée, autochtonisée et a-temporalisée de la culture basque.

En septembre 2005, le conseiller général socialiste Jean Espilondo, membre du Cercle Lissagaray, se dit, lui aussi, « très attaché aux valeurs républicaines c'est-à-dire l'universalisme, la citoyenneté. Les gens ne sont plus considérés selon leur religion, leur groupe humain, mais ils sont considérés comme égaux, comme citoyens. [...] La Révolution voulait casser les anciennes provinces, les anciens régimes et établir la responsabilité politique des gens sur la citoyenneté et non pas sur l'appartenance raciale, ethnique et provinciale $»^{8}$.

S'appuyant sur une rhétorique revendiquée comme issue des idéaux de la Révolution française et des Lumières, les positions du militant de CAP Vivre-Ensemble et de Jean Espilondo font de l'idée de race une valeur. En cela, leurs témoignages illustrent le fait que les idéaux républicains s'inscrivent dans un contexte raciologique dans la mesure où les idées d'assimilation, d'intégration et d'insertion en sont indissociables (Amselle, 1999 : Préface II, III). En effet, Jean Espilondo part du présupposé selon lequel l'identité provinciale relèverait nécessairement de l'« ethnique » et du « racial». De même, notre témoin de CAP Vivre-Ensemble, considère le cadre républicain comme la condition de l'émergence d'une « communauté de destin basée sur des ethnies ou populations très diverses ». Ici encore ce n'est pas l'idée de race en elle-même qu'il rejette, il ne remet nullement en cause l'assimilation entre culture basque, autochtonie et ethnicité. Au contraire, il s'en sert. Ce qu'il souhaite, c'est la fusion des différentes supposées races ou ethnies. Il fait donc de ces différences culturelles, de ces supposées entités figées, des différences a-historicisées, raciales.

C'est pourquoi il faut différencier lesidéaux républicains del'usage militant républicaniste et nationaliste français qui en est aujourd'hui fait par l'opposition à la reconnaissance politique de la culture basque. Par ailleurs, il nous faut ici constater que la nation française n'est pas strictement politique et volontariste. Elle n'est pas strictement citoyenne comme en témoigne

7.- Entretien avec un membre de l'association CAP Vivre-Ensemble, le 27 janvier 2000.

8.- Entretien avec Jean Espilondo, le 27 septembre 2005. 
notamment le fait, qu'historiquement, la République s'est efforcée « en particulier à travers son école publique, de donner à la France une origine et aux Français une ascendance collective, avec la Gaule et les Gaulois » (Gossiaux, 2002 : 49).

Ainsi, la construction de l'État-nation français républicain a donc suscité la naissance de différents types de représentations de la culture dite régionale. Selon les opposants à la reconnaissance publique du monde basque, la culture locale ne se traduirait qu'en termes essentialistes, qu'en référence à la « loi de la jungle », dans la mesure où elle n'est qu'une culture populaire rurale, orale et apolitique. Sont ici distingués deux pôles, le premier contenant les notions de cité, de politique et de progrès et renvoyant à l'idée de République française et, le second, incarné par les images auxquelles renvoient les notions de «jungle », d'irrationnel et l'idée de stagnation, qualifiant l'autochtonie du monde basque. Nous nous trouvons donc devant un système de hiérarchisation classique qui distingue le civilisé du sauvage, le civilisé du barbare et, au final, le citoyen de l'autochtone. Or, derrière ces épithètes de civilisé et de barbare se dissimule un même jugement : "Il est probable que le mot barbare se réfère étymologiquement à la confusion et à l'inarticulation du chant des oiseaux, opposées à la valeur signifiante du langage humain ; et sauvage, qui veut dire «de la forêt», évoque aussi un genre de vie animale, par opposition à la culture humaine. Dans les deux cas, on refuse d'admettre le fait même de la diversité culturelle ; on préfère rejeter hors de la culture, dans la nature, tout ce qui ne se conforme pas à la norme sous laquelle on vit » (Lévi-Strauss, 2001 : 44).

Ainsi, pour les opposants à la départementalisation du Pays basque nord, la culture basque est une culture « régionale ethnique » et, en cela, inapte à l'évolution, à la mobilité et, par voie de conséquence, inapte au progrès. Le monde basque est dans ce cas considéré comme un espace périphérique à la cité, comme un monde à part, à l'image de la « forêt » dont parle Claude Lévi-Strauss. À l'inverse, la culture nationale, c'est-à-dire la Culture académique française est vécue comme structurellement apte à pouvoir concilier valeurs politiques universalistes et Haute culture. C'est une culture pleinement humaine puisque mobile et apte au progrès au contraire du monde basque considéré comme figé et rétrograde par nature. Cette différenciation entre cultures et/ou sociétés à progrès et cultures et/ou sociétés pensées comme naturellement incompatibles avec toute culture politique conditionne aujourd'hui largement la nature du traitement politique de ce qu'il est convenu d'appeler la question basque.

\section{Sociétés historiques et à progrès contre culture a-historique et stagnante ?}

La hiérarchisation des cultures - et, à terme, des identités - s'opère alors à partir d'un argument fondateur : l'argument de l'histoire. Les catégories anthropologiques telles la culture ou l'identité sont en effet largement utilisées dans le discours des acteurs. Au sein de l'opposition au projet de départementalisation du Pays basque nord, l'interrogation suivante, ici sous les mots d'un opposant anonyme et non-encarté, tient lieu d'argument : " Mais enfin, le Pays basque a-t-il déjà été... Y a-t-il déjà eu un Pays basque indépendant, politiquement uni ?». Sous cette forme, la question contient la réponse et les conséquences qu'elle suppose. Cette interrogation conduit, du fait même de sa structure, à valider le présupposé de l'a-historicité du monde basque, affirmation initiale permettant de conclure à l'illégitimité des revendications d'entrée de la culture basque dans la sphère publique. À partir de l'emploi fréquent de ce type d'argument, les opposants à la départementalisation, à savoir l'association Citoyens en 
Adour-Pyrénées Vivre-Ensemble et le Cercle Lissagaray, légitimisent l'usage de l'argument de l'Histoire. Ainsi, paradoxalement, ces associations qui rejettent tout argumentaire basé sur des références historico-culturelles, raisonnent finalement, ici sous les mots d'un militant de CAP Vivre-Ensemble, à partir des mêmes principes :

«Par rapport à la Soule ${ }^{9}$, [la revendication du] département martèle des choses qui, sur le terrain, ne sont pas vraies. C'est quand même encore assez enclavé la Soule, et ils sont quand même plus tournés vers Navarrenx, Oloron, et le Béarn, ce sont leurs premiers voisins. Ils ont des relations, là aussi, ancestrales. Donc, expliquer qu'il y a trois provinces basques et que c'est autour de cela que le département doit se faire,... Il y en a, en Soule, qui ne sont même pas forcément d'accord $»^{10}$.

Lopposition au projet s'appuie ici sur les mécanismes dialectiques qu'elle a, au préalable, dénoncés et qu'elle dit vouloir combattre. Elle a recours, pour construire son raisonnement, à des arguments de type ethnoculturel. Aussi, selon le même militant, les villes et villages, «Bayonne, Boucau, Bidache, Sames, Guiche, le Seignanx, qui sont fortement revendiqués comme devant être partie intégrante du Département Pays Basque [n’ont] jamais été basques ». Il ajoute qu'« à Bayonne, les premiers écrits de la ville sont en gascon, c'est le livre d'or des évêques, je n'en fais pas une affaire, mais il ne faut pas occulter cela ». Historiquement, le gascon fut en effet au Pays basque une langue de Chancellerie, de l'administration, pas seulement à Bayonne, où les registres médiévaux des délibérations du corps de ville étaient rédigés en cette langue, mais aussi dans les noyaux urbains de la Navarre aux XI-XIII's siècles comme Sangüesa, Estella, Puente la Reina, ou les quartiers de Saint-Cernin et Saint-Nicolas à Pampelune. De même, les habitants des villes côtières du Guipúzcoa et de la Biscaye, comme Pasajes, Saint-Sébastien, Bermeo utilisèrent le gascon parfois jusqu'au XIXe siècle (Jean Goyhenetche : 1992).

Il reste que l'usage de l'argument de l'Histoire apparaît ici comme la manifestation de l'emploi remanié de la distinction idéologique entre sociétés à histoire et sociétés sans histoire. Lidée de sociétés à histoire permet de faire référence à des sociétés historiques, pensées comme structurellement sujettes au concept de progrès. La « société française » relèverait de cette condition. Lidée de sociétés sans histoire sert à désigner des sociétés définies comme intrinsèquement étrangères à la notion de progrès. Aux yeux des opposants à l'entrée en politique de la culture basque, la société basque s'inscrit dans cette catégorie. Dans le cadre de cette distinction - qui est une croyance -, l'argument de l'Histoire permet de désigner le vrai du faux, le juste de l'injuste et, à terme, conduit à ne concevoir comme légitime que l'historique ou plutôt ce que le sens commun et/ou académique conçoit comme tel. Or, cette différenciation entre sociétés à histoire et sociétés sans histoire est une construction. Dans son ouvrage Race et histoire, Race et culture, Claude Lévi-Strauss écrit :

9.- La Soule est l'une des trois provinces historiques du Pays basque de France. 10. - Ibid. note 6. 
«On parle volontiers des «peuples sans histoire» (pour dire parfois que ce sont les plus heureux). Cette formule elliptique signifie seulement que leur histoire est et restera inconnue, mais non qu'elle n'existe pas. Pendant des dizaines et mêmes des centaines de millénaires, là-bas aussi, il y a eu des hommes qui ont aimé, haï, souffert, inventé, combattu. En vérité, il n'existe pas de peuples enfants ; tous sont adultes, même ceux qui n'ont pas tenu le journal de leur enfance et de leur adolescence » (Lévi-Strauss, 2001 : 59).

Claude Lévi-Strauss pointe ici l'un des arguments auxquels ont recours les discours de type paternaliste : l'attribution de la condition d'a-historicité est compensée par l'idée d'accès structurel, naturel, au bonheur. Le déni d'historicité - et, en cela, d'humanité - est compensé par la chance, le privilège, d'être hors-Histoire donc hors-souffrance. Les peuples sans histoire connaîtraient la chance du bonheur originel et éternel, celui du bonheur de ne pas être ou, plus exactement, celui du bonheur de ne pas devenir, d'être stagnant, d'être autochtone, peuples premiers et ethnies statiques. Dans le cas basque, cette thématique du bonheur originel prend largement forme dans l'image mythique du Basque insouciant chantant et dansant aux pieds des Pyrénées et ce, de toute éternité, dans son jardin d'Eden. L'image du Basque bondissant, du Basque en quelque sorte indianisé, relève également de cette représentation paternaliste.

Dans ce cadre idéologique sous-jacent, l'opposition au projet départementaliste introduit l'idée que le Pays basque n'a jamais été politique, l'étape suivante consistant à en déduire qu'il n'a jamais été historique et, qu'en cela, il n'y a aucune raison légitime pour qu'il le devienne. Mais comme le souligne Claude Lévi-Strauss, plus loin dans son essai, «l'historicité, ou, pour parler exactement, l'évènementialité d'une culture ou d'un processus culturel sont ainsi fonction, non de leurs propriétés intrinsèques, mais de la situation où nous nous trouvons par rapport à eux, du nombre et de la diversité de nos intérêts qui sont gagés sur eux » (idem : 71). Or, la construction de l'État-nation républicain et, plus particulièrement, l'édification d'une culture académique en France - c'est-à-dire d'une norme culturelle officielle dont la valeur et la légitimité sont garanties par une institution - a parallèlement suscité la construction des cultures dites régionales. C'est pourquoi, de nos jours, en Pays basque nord, la culture basque, vécue et majoritairement assumée sous sa condition régionale, est perçue comme structurellement non-apte à participer au champ de la citoyenneté ${ }^{11}$. Historiquement, elle ne relève pas de la sphère du politique, elle n'est examinée que comme une culture populaire au sens de culture vulgaire et, en cela, que comme une culture du peuple et non de la nation. Dans le cadre national, elle ne revêt pas de temps historique, ou plutôt, elle ne relève que de l'immémoriel - incarné dans le «mystère de l'énigme basque »-, ce qui, au final, du point de vue symbolique, revient au même.

Aussi, nier le fait que la culture basque ait nécessairement un parcours historique, l'exclure du temps historique revient à raisonner, selon les termes de l'africaniste Jean-Loup

11.- Une enquête de l'Institut Culturel Basque-Euskal Kultur Erakundea, menée 2004-2005 sur l'ensemble du Pays basque transfrontalier et intitulée, Pratiques culturelles et identités collectives en Pays basque, a montré qu'au sein de la population du Pays basque nord la représentation régionale de l'identité basque était la plus répandue. Cette représentation « régionale » de l'appartenance basque est implicitement construite autour de l'idée d'après laquelle l'euskara n'est pas la langue du « Territoire Pays Basque » mais la langue du groupe basque, considéré comme un groupe étanche. 
Amselle, à partir d'« une logique de l'imputation qui est omniprésente dans les processus d'identification : le fait de poser des catégories négatives, comme celles de société sans État, de société sans écriture, de tribu ou d'ethnie permet en réalité d'affirmer la supériorité de nos États-nations lettrés » (Amselle, 1999 : 113).

C'est dans ce contexte historique qu'il faut replacer la construction de l'idée d'atemporalité et d'immuabilité du monde basque sur laquelle s'appuie le discours antidépartementaliste. La culture académique française, issue de la construction de l'Étatnation, est considérée par l'opposition aux revendications basquisantes comme incarnant de fait un temps historique légitime puisque politiquement officiel - ce d'autant plus que ce temps naît d'une révolution progressiste, la Révolution française, laquelle incarne le point de départ de cette temporalité politique. À l'inverse, la culture basque est considérée comme ne pouvant être que stagnante dans la mesure où historiquement - du moins, l'opposition à la départementalisation l'instrumentalise-t-elle - elle n'a jamais été le cadre de développement d'une organisation politique spécifique ni même bénéficié d'un cadre politique autonome. Présentée sous cet angle, c'est une culture qui, du point de vue politique, ne peut mener qu'au communautarisme ethniciste. Or, lire le monde basque sous cet angle revient à adhérer à l'idée d'une culture basque par nature figée et finie. Les opposants à la reconnaissance institutionnelle du monde basque instrumentalisent cette idée pour faire des revendications basques des aspirations nécessairement ethnicistes. Il y a en effet dans l'argumentaire antidépartementaliste l'instrumentalisation d'une idée sous-jacente: la supposé a-historicité, étanchéité du groupe basque. C'est l'idée, au final, du monde basque comme ethnie c'està-dire comme isolat culturel et communautaire. Pour le sens commun, cette idée d'ethnie renvoie à percevoir la culture basque comme une culture ne concernant que les autochtones ou, autrement dit, que les individus estampillés comme représentants les derniers indigènes des Pyrénées.

Il y a donc derrière le discours opposé à l'entrée en politique de la culture basque, distinction entre deux formes d'Histoire, deux types d'humanités: une humanité nationale, apte au progrès car apte à l'histoire et, une humanité régionale, inapte au progrès car de nature nécessairement stagnante. Cependant la distinction entre ces deux formes d'Histoire ne dépend évidemment pas de la nature intrinsèque des cultures auxquelles on l'applique, mais de la perspective dans laquelle l'acteur se place pour évaluer une culture différente:

« Nous considérerions ainsi comme cumulative toute culture qui se développerait dans un sens analogue au nôtre, c'est-à-dire dont le développement serait doté pour nous de signification. Tandis que les autres cultures nous apparaîtraient comme stationnaires, non pas nécessairement parce qu'elles le sont, mais parce que leur ligne de développement ne signifie rien pour nous, n'est pas mesurable dans les termes du système de référence que nous utilisons » (Lévi-Strauss, 2001 : 69-70).

Aussi, le système de références de l'opposition aux revendications institutionnelles basques consiste à établir une distinction entre sociétés modernes à progrès - puisque historiques - et sociétés anciennes, statiques et sans histoire - puisque figées dans la répétition du même et, en cela, conservatrices voire réactionnaires par nature. À partir de ces considérations, toute forme d'institution politique pensée comme pouvant être appliquée au sujet Pays basque est considérée comme incompatible avec sa nature même. 
Cette distinction première, cette discrimination initiale entre condition citoyenne (la culture française) et condition autochtone ethnique (la culture basque), est également à la source des diverses représentations du rôle supposé des langues au sein du Pays basque français contemporain. C'est la croyance en cette distinction qui conditionne le rejet de l'entrée de la langue basque dans la sphère publique. Dans ce cas, l'opposition au projet départementaliste perçoit l'euskara, sous l'angle de la métaphore de Claude Lévi-Strauss, comme le « chant des oiseaux » des «sauvages » de la « forêt ».

L'ethnologie, en tant que discipline scientifique a historiquement offert les outils conceptuels permettant la construction idéologique de ces deux espaces antagoniques de représentations : la citoyenneté et l'ethnicité. Dans le cadre d'un lent processus initié à partir du XVII ${ }^{e}$ siècle, le monde basque a étél'objet d'un phénomène d'ethnologisation, d'autochtonisation ou, autrement formulé, de disqualification à l'accès à la sphère publique. La culture basque a en effet subi la tendance de l'anthropologie à se déployer « sous la forme de différents paradigmes - ethnos/polis, sauvage/barbare/civilisé, société primitive/société industrielle, société sans État/société à État - qui, dès lors qu'ils sont énoncés, ont immédiatement pour effet de distribuer toute une série de populations dans des catégories distinctes » (Amselle, 1999 : 39). Ainsi, il y a un lien entre la rhétorique anti-départementaliste - qui s'appuie sur une représentation ethnologisée de la culture basque - et la typologie scientifique, d'origine évolutionniste et fonctionnaliste, opposant sociétés sans État et sociétés étatiques : certaines cultures auraient par nature la propension à édifier l'État, d'autres non. Mais dans le cas qui nous intéresse, la distinction sociétés historiques/sociétés sans histoire n'a de sens qu'en tenant compte du cadre historique et idéologique particulier à partir duquel elle s'opère, à savoir la description du fait basque, essentiellement à partir du XIX ${ }^{e}$ siècle, sur le mode de sa supposée a-historicité, de sa supposée étanchéité : à l'image des « sociétés stagnantes » ou « sociétés froides » définies par Claude Lefort, la société basque aurait vécue « en dehors de l'ère de développement historique », sans conscience historique du passé, du moins au niveau de l'expression publique et écrite, sans connaissance historique (Lefort, 1978).

\section{Conclusion}

Nous avons vu que la distinction entre culture légitime publique (la citoyenneté française) et culture a-légale privée (l'autochtonie basque) idéologiquement perçue comme destinée par nature à le rester, est la condition nécessaire à la formation d'un discours antidépartementaliste se réclamant de la «défense de la République ». Nous avons également montré que tout en rejetant l'usage politique des référents culturalo-identitaires, l'opposition à toute revendication institutionnelle du Pays basque de France fait de la question identitaire son terrain rhétorique privilégié par l'instrumentalisation de l'idée, toujours sous-jacente, de l'existence d'un communautarisme, dans le sens péjoratif du terme, voire d'un racisme basque. Or, la construction de l'idée de race basque - et de son usage métaphorique actuel par l'intermédiaire de la notion d'ethnie basque - ne peut s'analyser indépendamment de l'historiographie et de l'anthropologie du XIXe siècle. Cette idée de race ou d'ethnie basque constitue aujourd'hui le socle théorique à partir duquel la distinction entre « sociétés sans État » (le cas basque) et « sociétés à État » (la République française) - et celle synonyme de « sociétés sans histoire » et de « sociétés à histoire »- prend forme. 


\section{Bibliographie :}

Amselle, Jean-Loup. 1999. Logiques métisses, anthropologie de l'identité en Afrique et ailleurs. Paris:Éditions Payot \& Rivages.

De Certeau, Michel, Julia Dominique \& Revel Jacques. 1975. Une politique de la langue, Paris: Éditions Gallimard.

Oronos, Michel. 2002. Le mouvement culturel basque, 1951-2001. Bayonne: Éditions Elkar, Bayonne.

Gossiaux Jean-François, Pouvoirs ethniques dans les Balkans, Presses Universitaires de France, Collection Ethnologies, Paris, 2002, 217 p.

Goyhenetche Jean, Les Basques et leur histoire, Mythes et réalités, Éditions Elkar, Bayonne, 1992, $353 \mathrm{p}$.

Lefort Claude, Les formes de l'histoire, essais d'anthropologie politique, Éditions Gallimard, Folio Essai, Paris, 1978, 569 p.

Lévi-Strauss Claude, Race et histoire, Race et culture, Albin Michel/Éditions UNESCO, Idées, Paris, 2001, 173 p.

Pierre Thomas, Controverses institutionnelles en Pays basque de France. Usages politiques et déconstructions des préjugés socioculturels, Paris, L'Harmattan, Anthropologie du monde occidental, 2010, 303 p. 